\title{
A Review of Electronic Devices to Assess Inhaler Technique
}

Delesha M. Carpenter, PhD, MSPH

Eshelman School of Pharmacy, University of North Carolina, Asheville, NC

Courtney A. Roberts, MSPH

Eshelman School of Pharmacy, University of North Carolina, Chapel Hill, NC

Adam J. Sage, MA

Eshelman School of Pharmacy, University of North Carolina, Chapel Hill, NC

Johnson George, PhD

Pharmacy and Pharmaceutical Sciences, Monash University, Melbourne, Australia

Robert Horne, PhD

School of Pharmacy, University College London, London, United Kingdom

\section{Correspondence:}

Delesha M. Carpenter

Eshelman School of Pharmacy

CPO 2125

Asheville, NC 28804

Phone: 828-250-3916

dmcarpenter@unc.edu

Keywords (up to 6): inhaler, metered dose inhaler, dry powder inhaler, inhaler competence, inhaler technique, mHealth 


\section{ABSTRACT (150 words)}

Purpose of review: Multiple digital devices exist that provide feedback on the accuracy of patient inhaler technique. Our purpose is to describe the inhaler technique feedback provided by these devices, including specific technique steps measured, how feedback is displayed, target of feedback (patient, provider, researcher), and compatibility with inhaler type (metered-dose inhaler, diskus, other).

Recent findings: We identified eight devices that provide feedback on inhaler technique. Only one device assessed all evidence-based technique steps. Most devices provide limited real-time feedback to patients, if any feedback at all.

Summary: Technologies to assess inhaler technique are advancing and hold great potential for improving patient inhaler technique. Many devices are limited in their ability to detect all evidence-based technique steps and provide real-time user-friendly feedback to patients and providers. Usability tests with patients and providers could identify ways to improve these devices to improve their utility in clinical settings. 


\section{Introduction (4,000 words, 1 figure, 2 tables)}

Asthma is projected to affect 400 million people worldwide by $2025,{ }^{1}$ and currently affects more than 25 million people in the U.S. ${ }^{2}$ The economic burden of asthma is substantial, having been estimated at $\$ 56$ billion per year in direct and indirect costs. ${ }^{3}$ Individuals with poorly controlled asthma have greater medical expenditures, use health services more often, and report more negative impact on work life and psychological health than individuals with controlled asthma., ${ }^{4,5}$

Asthma control can be improved and costly negative sequel can be prevented when patients take medications appropriately. ${ }^{6-8}$ Unfortunately, many asthma interventions that target medication use focus exclusively on medication adherence or give minimal attention to inhaler technique, also referred to as inhaler competence. ${ }^{9}$ Because improper technique can compromise delivery of inhaled medications to the lungs, ${ }^{10}$ patients with incorrect technique are significantly more likely to have poorly controlled asthma and more emergency department visits. ${ }^{11-13}$ The potential for inhaler technique interventions to improve asthma outcomes is substantial given that up to $92 \%$ of children ${ }^{14-16}$ and $96 \%$ of adults ${ }^{17,18}$ demonstrate significant deficiencies in inhaler technique.

Due to a number of barriers, including time constraints, providers often do not educate patients about how to use inhalers correctly during office visits. ${ }^{14} \mathrm{New}$ electronic devices could provide a more streamlined and standardized method to educate patients about how to use their asthma inhalers in clinical settings. Indeed, two review articles documented that several digital inhaler monitoring devices are available to assess inhaler technique. ${ }^{9}\{$ Lavorini, $2010 \# 1575\}$ These reviews have documented 
that digital devices can validly and reliably assess patient inhaler technique, especially as it relates to inhalation maneuvers. However, these reviews are either outdated (published in 2010) or lack details about the specific technique steps assessed by the devices and the manner in which technique feedback is presented to providers and patients.

Our purpose was to update and enhance previous research to describe the nature of inhaler technique feedback provided by electronic devices, with a focus on factors that could influence the utility and uptake of these devices in clinical settings. We specifically focus on: a) the specific technique steps assessed by the device; b) how feedback is presented; c) target of feedback (patient, clinician, researcher), d) compatibility with inhaler type (metered-dose inhaler [MDI], diskus, other dry powder inhaler [DPI]); e) cost; and f) whether the device is FDA-approved.

\section{Methods}

A systematic review of the literature and patents was conducted in November 2016 to identify electronic devices capable of assessing inhaler technique. Figure 1 summarizes our review and selection process.

Search strategy. We first used PubMed to identify articles that described digital inhaler-based devices. We used the same search terms as a recent review of digital inhaler-based health monitoring devices that was completed in August 2015. ${ }^{9}$ In order to identify any new devices that may have been reported in the literature since August 2015, we searched articles that were published between August 2015 and November 2016. The specific search terms used were: 
(("electronic" OR "monitoring" OR "sensing") AND "inhaler") OR ("Nebulizer Chronolog" OR "MDI Chronolog" OR "Aerosol Actuation Counter" OR "Turbuhaler Inhalation Computer" OR "Doser" OR "Electronic Diskhaler" OR "SmartMist" OR "MDILog" OR "Diskus Adherence Logger" OR "Smart Inhaler Tracker" OR "SmartTrack" OR "SmartDisk" OR "SmartTurbo" OR "SmartFlow" OR "SmartMat" OR "Inhaler Compliance Assessment Device" OR "INCA" OR "Asthmapolis" OR "Propeller Health" OR "Chameleon" OR "SmartTouch" OR "MDI Acoustic Actuation Detector" OR "pMDI Datalogger" OR "Geckocap" OR "CareTRx" OR "Inspiromatic" OR "Sensohaler" OR "T-Haler")

In addition to the PubMed review, we examined references of important full-text articles for potentially missed devices and included relevant devices that were described in the previous review articles\{Lavorini, $2010 \# 1575\}\{$ Kikidis, $2016 \# 1470\}$ that were not captured in our PubMed search. These search strategies yielded 539 articles.

We also conducted a patent search in order to identify devices that have been developed or are currently in development to assess inhaler technique that may have not yet been published in the peer-reviewed literature. Patent searches were conducted using Thomson Innovation (http://info.thomsoninnovation.com), which includes multiple databases of patents and patent applications from the U.S., Europe, World Intellectual Property Organization (WIPO), China, and several other geographies. The Derwent World Patents Index (DWPI) is accessible within the Thomson Innovation tool, enabling searching of English language abstracts from expert human editorial staffers, with an indexing system and patent families that group inventions across geographic filings. Within these databases, we conducted a search of patent titles, abstracts, and claims of 
patents and patent applications from January 1988 to December 2016 using the following query:

((inhaler ${ }^{\star}$ OR inhalation) AND (asthma)) AND ((sensor ${ }^{\star}$ OR track* OR monitor ${ }^{*}$ OR record* OR display* NEAR10 (use OR efficien* OR compliance)).

NEAR10 means the search included abstracts in which the words "use," "efficien" or "compliance" were within 10 words of any of the other search criteria words. This search yielded 125 potentially relevant patents.

Selection criteria. For the literature search, we first reviewed the titles of the 539 articles for potential relevance. Articles $(n=31)$ with titles that referenced: 1$)$ inhaler adherence and/or technique; 2) using an asthma monitoring device or sensor; or 3) the name and/or application of an inhaler-based monitoring device that was identified in previous reviews were selected for abstract review $(n=31)$. To reduce bias, three individuals (CR, AS, DC) met to review these 31 abstracts to determine which articles would be selected for further full-text review. Of these 31 articles, 12 described devices that were capable of assessing at least one patient inhaler technique step and were selected for full-text review.

Patent search results were reviewed for relevancy by a research analyst (AS), who identified 125 potentially relevant patents. Using the same selection criteria as the literature review, the analyst reviewed the titles and abstracts for each patent and identified 18 patents for further full-text review by second reviewer (DC). During full-text review of the 18 patients, both reviewers came to a consensus on which patents to include for data abstracting $(n=2)$. 
Exclusion criteria. Devices identified during the literature search and patent review were excluded if: 1) the device exclusively assessed medication adherence; 2 ) the device was developed to alter the manner in which the drug was delivered rather than to assess technique; 3 ) the device did not assess at least one essential inhaler technique step as defined by the Aerosol Drug Management Improvement (ADMIT) Team (see data extraction and analysis for more information on essential steps). ${ }^{19}$ Additionally, we excluded one patent result that duplicated a device that was identified during the literature search.

Data extraction and analysis. We extracted the following information for each device: 1) name of device; 2) which inhaler technique steps the device assesses; 3) how inhaler technique feedback is displayed; 4) the target of inhaler technique feedback (patient, clinician, researcher); 5) device compatibility (metered dose inhaler [MDI], diskus, other); 6) cost of device; and 7) whether the device is FDA approved (yes/no).

The specific steps assessed by each device was cross-checked against the list of essential technique steps for MDI and diskus as identified in a recent review of the inhaler technique literature by the Aerosol Drug Management Improvement Team (ADMIT). ${ }^{19}$ According to ADMIT ${ }^{19}$, the five essential steps for a metered dose inhaler (MDI) include: 1) prepare the device [uncap, shake, and hold inhaler vertically], 2) breathe out completely, 3) place teeth and lips around mouthpiece and press canister once while inhaling slowly and deeply, 4) breathe in slowly and deeply, and 5) hold breath for 5-10 seconds. The essential steps for a diskus are:1) prepare the device [uncap, load the inhaler], 2) turn away from the inhaler and breathe out completely, 3) place teeth and lips around the mouthpiece to form a seal, 4) breathe in with one brisk, 
deep inhalation, and 5) hold the breath for 5 to 10 seconds or as long as possible. In order to ensure that our results were as complete as possible, we supplemented missing information from the article and patent search using one or more of the following strategies: 1) contacting the corresponding author of the article and/or device manufacturer (if known); 2) searching for the devices name on Google; and 3) searching for videos about the device on YouTube.

\section{Results}

Table 1 presents an overview of the 7 devices included in the review.

Steps assessed. No devices were capable of assessing all essential technique steps for an MDI. One device (add INCA ref) assessed all five essential steps for a diskus. Devices most commonly assessed steps related to patients' breathing patterns (i.e., timing, force, and length of inhalation and exhalation). Four devices (X\%) had the ability to detect with an MDI inhaler was shaken. Table 1 presents information about the specific steps assessed by each device.

How feedback displayed. Feedback on inhaler technique was most commonly provided in real-time in the form of colored green or red lights (3 devices, $x \mathrm{x} \%$ ). Two devices provided real-time feedback in the form of digital displays that incentivized correct technique. For example, the T-haler showed a green dot moving into a "correct" box when the patient's inhalation was optimal. Two devices did not provide any realtime feedback; data was recorded, downloaded, and viewable in a spreadsheet.

Target of feedback. Three devices $(x \%)$ were targeted specifically to patients, 2 $(\mathrm{X} \%)$ to clinicians, and $1(\mathrm{X} \%)$ to researchers. One device (INCA) could be used by clinicians, researchers, and patients, but patients would need someone to help them 
interpret the meaning of the audiofile to understand how the soundwaves relate to technique steps. The AIM is targeted for clinicians, but the nature of its feedback suggests that it could also be readily understood by patients. The SmartMist provides feedback on technique that is interpretable by both clinicians and patients.

Device compatibility. The majority of devices $(6 ; 86 \%)$ were compatible with MDIs. Three devices (add ref for pMDI datalogger article cited by Kikidis and Smartmist ref) were compatible with MDIs and spacers. Fewer devices are compatible with DPIs. Specifically, three devices, the INCA (add INCA cites), AIM (add AIM website), and Mag-Flo (Mag-flow website) are designed for use with a diskus. The Mag-Flo is also compatible with turbuhalers.

Cost. Cost information was only available for one device. The AIM costs $\$ 405$. FDA approval. Four devices (XX\%) had received FDA approval.

\section{Discussion}

This review summarizes key aspects of devices that have been developed to assess patient inhaler technique. Although several devices are currently available to assess inhaler technique, many have limitations as it relates to providing feedback on all essential technique steps or displaying feedback to providers and patients in a userfriendly format. Few devices are available to assess technique for DPIs, especially turbuhalers and newer devices like Ellipta. Despite limitations with existing devices, there is significant opportunity to use these devices in clinical settings to instruct patients on proper use of their inhalers.

Currently, no device provides feedback on all essential inhaler technique steps for MDIs, and only one device provides feedback on all essential diskus steps. Although 
the MDI-compatible devices do not address all essential steps, they do provide feedback on the steps that are most difficult to assess with the naked eye (i.e., timing, force, and length of inhalation and exhalation). Many of these devices also provide feedback on whether the patient shook their inhaler, which is a commonly missed step.\{Sleath, $2011 \# 394\}\{$ Lavorini, $2010 \# 1575\}$ For these reasons, when coupled with feedback from a provider that addresses steps that these devices cannot measure (e.g., uncapping the inhaler and holding the inhaler vertically), these devices can provide useful information about the patient's technique.

Feedback on inhaler technique is most commonly provided to patients in verbal format by their providers. Although provider feedback on technique is an effective teaching method, observational studies have documented that technique demonstrations occur in just $12 \%$ of office visits. ${ }^{14,20}$ Low rates of inhaler technique instruction persist despite national guidelines that recommend inhaler technique skills should be demonstrated at every patient visit. ${ }^{21}$ Perceived time constraints and the number of health topics that need to be addressed during a typical office visit could potentially limit providers' ability to engage in inhaler technique instruction. Thus, devices that provide automated technique feedback to patients could potentially enhance the ability of providers to provide technique education at every patient visit by reducing the amount of time necessary to assess patient's device technique. Repeated instruction is especially desirable given that deterioration in technique has been documented as early as one month after receiving technique education \{Basheti, 2007 \#819;Kamps, 2000 \#788;Carpenter, 2014 \#1129\}\{Lavorini, 2010 \#1575\}. 
In addition to providing technique feedback in a time-efficient manner, inhaler technique devices can also provide tailored feedback to providers and patients on the specific steps that patients perform incorrectly. A large body of research has shown that tailored messages are more likely to be remembered and are more successful in influencing health behavior change than generic messages. ${ }^{23-25}$ Specific to inhaler technique, one small pilot study found that videos that were tailored to patient demographic characteristics and the specific steps patients missed led to significant improvements in inhaler technique that were maintained at 1-month followup.\{Carpenter, $2016 \# 1429\}$ According to Social Cognitive Theory, mastery experience (or doing something correctly) is the most effective way to foster self-efficacy. ${ }^{26,27}$ Thus, if patients are made aware of the specific inhaler steps that they perform incorrectly in real-time, they can immediately correct those errors, which could increase their confidence to use their inhalers correctly (e.g. inhaler self-efficacy) and ultimately lead to better inhaler technique.

There is also potential for these devices to improve patient inhaler technique in the home environment. Although none of these devices were intended for use outside of the clinical setting, daily feedback on inhaler technique may help ensure patients are using their inhalers correctly, especially for patients who receive a new prescription for an inhaler. In order to be feasible for home use, devices must be portable, affordable, and provider feedback to the patient in user-friendly and understandable manner. Two of the devices described in this review used real-time feedback to incentivize correct inhaler use. This type of feedback may be especially helpful for helping new inhaler users master appropriate inhaler technique. 
Based on our findings, we suggest $\mathrm{X}$ main areas for future directions for development and evaluation of inhaler technique assessment devices. The first is related to device development; the development of devices that are capable of assessing all essential steps for MDIs and non-diskus DPIs are warranted. Second, device developers should involve target users (i.e., patients, providers) in the design process to ensure that feedback provided by the device is easily interpretable. Devices that provide feedback that is difficult to understand could limit device adoption and lower users' perceptions of the devices' utility. Adam- can you add a usability standards sentence here. Third, comparative effectiveness trials which evaluate the effectiveness of these devices at improving inhaler technique should be conducted. Such trials could compare the effectiveness of: 1) devices compared to one another and 2) devices compared to provider instruction and multimedia instruction (e.g., videos).

\section{$\underline{\text { Limitations }}$}

Our review of articles and patents was completed in December 2016. It is possible that newer devices are now available on the market and that we did not capture all devices in our search of the literature and patents. It is also possible that some of these devices described in this article are no longer commercially available. We did not include devices for which the primary purpose is to assess a patient's inspiratory flow rate or inspiratory capacity to identify the best dry powder inhaler for them, even though these devices have the capability to assess specific technique steps related to correct inhalation.\{Lavorini, $2010 \# 1575\}$ Detailed information regarding the specific technique steps assessed, target of feedback, and method for providing technique feedback was lacking for several of the devices. Although we attempted to contact 
authors and/or manufacturers to obtain additional information, including information on cost, inadequate detail may have led us to inaccurately document specific aspects of the devices.

\section{Conclusions}

Inhaler technique, or competence, remains a relatively neglected area of patient education even though poor technique is associated with negative patient outcomes. ${ }^{11-}$ ${ }^{13}$ Electronic devices can provide a time-efficient and reliable way for healthcare providers to assess patient inhaler technique. Existing devices can provide objective feedback about correct technique for steps that are difficult to assess with the naked eye; such as whether the patient inhaled forcefully enough or coordinated inhaler actuation with inhalation. Our review identifies several areas of opportunity to make inhaler technique devices useful in clinical care and home settings. Major areas for improvement include developing devices to assess technique for non-diskus DPI inhalers and improving the quality of technique feedback so it is quickly and easily interpretable by patients and providers. Future research should explore whether these devices can facilitate providers' ability to conduct inhaler technique assessments during office visits. 


\section{References}

1. Masoli M, Fabian D, Holt S, Beasley R. The global burden of asthma: executive summary of the GINA Dissemination Committee report. Allergy. 2004;59(5):469478.

2. Akinbami LJ, Moorman JE, Bailey C, et al. Trends in asthma prevalence, health care use, and mortality in the United States, 2001-2010. NCHS data brief, no 94. Hyattsville, MD: National Center for Health Statistics2012.

3. Centers for Disease Control and Prevention. Asthma's Impact on the Nation-Data from the CDC National Asthma Control Program. 2014:1-4.

4. Sullivan PW, Ghushchyan VH, Campbell JD, Globe G, Bender B, Magid DJ. Measuring the Cost of Poor Asthma Control and Exacerbations. Journal of Asthma. 2016(just-accepted):00-00.

5. Bahadori K, Doyle-Waters MM, Marra C, et al. Economic burden of asthma: a systematic review. BMC pulmonary medicine. 2009;9(1):1.

6. Bartlett S, Lukk P, Butz A, Lampros-Klein F, Rand C. Enhancing medication adherence among inner-city children with asthma: results from pilot studies. Journal of Asthma. 2002;39:47-54.

7. Bauman LJ, Wright E, Leickly FE, et al. Relationship of Adherence to Pediatric Asthma Morbidity Among Inner-City Children. Pediatrics. 2002;110(1):e6.

8. Zeiger RS, Hay JW, Contreras R, et al. Asthma costs and utilization in a managed care organization. Journal of Allergy and Clinical Immunology. 2008;121(4):885-892. e885. 
9. Kikidis D, Konstantinos V, Tzovaras D, Usmani OS. The Digital Asthma Patient: The History and Future of Inhaler Based Health Monitoring Devices. Journal of aerosol medicine and pulmonary drug delivery. 2016;29(3):219-232.

10. Clark NM, Gong M, Kaciroti N. A model of self-regulation for control of chronic disease. Health Educ Behav. 2001;28(6):769-782.

11. AL-Jahdali $\mathrm{H}$, Ahmed $\mathrm{A}, \mathrm{AL}$-Harbi $\mathrm{A}$, et al. Improper inhaler technique is associated with poor asthma control and frequent emergency department visits. Allergy, Asthma \& Clinical Immunology. 2013;9(1):1-7.

12. Giraud V, Roche N. Misuse of corticosteroid metered-dose inhaler is associated with decreased asthma stability. European Respiratory Journal. 2002;19(2):246251.

13. Basheti IA, Reddel HK, Armour CL, Bosnic-Anticevich SZ. Improved asthma outcomes with a simple inhaler technique intervention by community pharmacists. Journal of Allergy and Clinical Immunology. 2007;119(6):15371538.

14. Sleath B, Ayala GX, Gillette C, et al. Provider Demonstration and Assessment of Child Device Technique During Pediatric Asthma Visits. Pediatrics. 2011;127(4):642-648.

15. Pedersen S. Inhaler use in children with asthma. Danish Med Bull. 1987;34 234249.

16. Pedersen SK, Frost L, Arnfred T. Errors in inhalation technique and efficacy of inhaler use in asthmatic children. Allergy. 1986;41 118-124. 
17. Toumas-Shehata M, Price D, Amin Basheti I, Bosnic-Anticevich S. Exploring the role of quantitative feedback in inhaler technique education: a clusterrandomised, two-arm, parallel-group, repeated-measures study. NPJ Primary Care Respiratory Medicine. 2014;24:14071.

18. Crane MA, Jenkins CR, Goeman DP, Douglass JA. Inhaler device technique can be improved in older adults through tailored education: findings from a randomised controlled trial. NPJ Primary Care Respiratory Medicine. $2014 ; 24: 14034$.

19. Sanchis J, Gich I, Pedersen S. Systematic Review of Errors in Inhaler Use: Has Patient Technique Improved Over Time? Chest. 2016.

20. Sleath B. Communication during pediatric asthma visits and child asthma medication device technique 1 month later. The Journal of asthma. 2012;49(9):918-925.

21. NHLBI. Guidelines for the Diagnosis and Management of Asthma: Expert Panel Report 3. 2007.

22. Kamps AWA, van Ewijk B, Roorda RJ, Brand PLP. Poor inhalation technique, even after inhalation instructions, in children with asthma. Pediatric Pulmonology. 2000;29(1):39-42 .

23. Noar SM, Benac CN, Harris MS. Does tailoring matter? Meta-analytic review of tailored print health behavior change interventions. Psychological Bulletin. 2007;133(4):673-693.

24. Skinner C, Campbell M, Rimer B, Curry S, Prochaska J. How effective is tailored print communication? Annals of Behavioral Medicine. 1999;21(4):290-298. 
25. Skinner CS, Strecher VJ, Hospers H. Physicians' recommendations for mammography: do tailored messages make a difference? American Journal of Public Health. 1994;84(1):43-49.

26. Bandura A. Human agency in social cognitive theory. American Psychologist. $1989 ; 44$ 1175-1184.

27. Bandura A. SOCIAL COGNITIVE THEORY: An Agentic Perspective. Annual Review of Psychology. 2001:1. 
TABLES

\begin{tabular}{|c|c|c|c|c|c|c|}
\hline Device Name & Steps Assessed & $\begin{array}{l}\text { How } \\
\text { Feedback } \\
\text { Displayed }\end{array}$ & $\begin{array}{l}\text { Target of } \\
\text { Feedback }\end{array}$ & $\begin{array}{l}\text { Device } \\
\text { Compatibility }\end{array}$ & Cost & $\begin{array}{l}\text { FDA } \\
\text { Approval }\end{array}$ \\
\hline $\begin{array}{l}\text { Inhaler } \\
\text { Compliance } \\
\text { Assessment } \\
\text { Device } \\
\text { (INCA) }\end{array}$ & $\begin{array}{l}\text { Diskus } \\
\text { 1) prepares the } \\
\text { device (uncaps and } \\
\text { shakes) } \\
\text { 2) breathes out } \\
\text { completely } \\
\text { 3-4) Inhales slowly } \\
\text { and deeply } \\
\text { 5) holds breath for } \\
\text { 5-10 seconds }\end{array}$ & $\begin{array}{l}\text { As a digital } \\
\text { audio } \\
\text { recording file } \\
\text { and in } \\
\text { calendar } \\
\text { format for } \\
\text { day/time used }\end{array}$ & $\begin{array}{l}\text { Clinician } \\
\text { Patient (if } \\
\text { audiofile } \\
\text { explained) } \\
\text { Researcher }\end{array}$ & $\begin{array}{l}\text { Diskus } \\
\text { MDI and } \\
\text { Elipta (in } \\
\text { development) }\end{array}$ & TBD & Yes \\
\hline $\begin{array}{l}\text { pMDI } \\
\text { datalogger }\end{array}$ & $\begin{array}{l}\text { 1) Shaking of } \\
\text { inhaler } \\
\text { 2-5) Records } \\
\text { breathing pattern of } \\
\text { patient while using } \\
\text { inhaler (including } \\
\text { inhalation and } \\
\text { exhalation time, } \\
\text { duration, and } \\
\text { volume) } \\
{ }^{*} \text { cannot assess } \\
\text { uncapping, inhaler } \\
\text { orientation, or } \\
\text { quality of lip seal }\end{array}$ & $\begin{array}{l}\text { Information } \\
\text { not displayed } \\
\text { in real-time } \\
\text { Information } \\
\text { recorded and } \\
\text { displayed in } \\
\text { Excel file } \\
\text { when } \\
\text { downloaded }\end{array}$ & Researcher & $\begin{array}{l}\text { MDI (with and } \\
\text { without } \\
\text { spacer) }\end{array}$ & $\begin{array}{l}\text { Not } \\
\text { published } \\
\text { AUTHOR: } \\
\text { Device } \\
\text { provided by } \\
\text { Respironics } \\
\text { for study and } \\
\text { doesn't } \\
\text { know } \\
\text { "suspect it is } \\
\text { quite high" }\end{array}$ & No \\
\hline $\begin{array}{l}\text { Aerosol } \\
\text { Inhalation } \\
\text { Monitor (AIM) }\end{array}$ & $\begin{array}{l}\frac{\mathrm{MDI}}{3-5)} \text { Correct } \\
\text { canister activation } \\
\text { (too early or not at } \\
\text { all), inhalation } \\
\text { rates, inhalation } \\
\text { times, breath hold } \\
\text { times } \\
\frac{\text { Diskus }}{\text { (add steps) }}\end{array}$ & $\begin{array}{l}\text { Real-time } \\
\text { feedback } \\
\text { provided on } \\
\text { device } \\
\text { screen; } \\
\text { indicator } \\
\text { lights (green, } \\
\text { yellow, red) } \\
\text { provide } \\
\text { feedback on } \\
\text { whether steps } \\
\text { performed } \\
\text { correctly }\end{array}$ & Clinician & $\begin{array}{l}\text { MDI (with and } \\
\text { without } \\
\text { spacer) } \\
\text { Diskus }\end{array}$ & $\$ 405.00$ US & Yes \\
\hline T-haler & $\begin{array}{l}\text { 1) Shaking of } \\
\text { inhaler } \\
3-4 \text { ) timing of } \\
\text { actuation and } \\
\text { inhalation flow rate } \\
\text { (and whether } \\
\text { patient inhaled } \\
\text { forcefully enough) }\end{array}$ & $\begin{array}{l}\text { Interactive } \\
\text { video game } \\
\text { that uses a } \\
\text { dot and grid } \\
\text { to show } \\
\text { patients when } \\
\text { the inhaled } \\
\text { properly }\end{array}$ & Patient & MDI & Unknown & Unknown \\
\hline Smartmist & $\begin{array}{l}\text { 3-4) slow and } \\
\text { steady inhalation }\end{array}$ & $\begin{array}{l}\text { Red or green } \\
\text { light }\end{array}$ & $\begin{array}{l}\text { Patient } \\
\text { Clinician }\end{array}$ & MDI & Unknown & Yes \\
\hline MDI log & $\begin{array}{l}\text { 1) shaking of } \\
\text { inhaler } \\
3-4 \text { ) inhaling slowly } \\
\text { and deeply (timing }\end{array}$ & $\begin{array}{l}\text { Not } \\
\text { displayed; } \\
\text { Downloaded } \\
\text { and printed }\end{array}$ & Clinician & MDI & Unknown & yes \\
\hline
\end{tabular}




\begin{tabular}{|c|c|c|c|c|c|c|}
\hline Device Name & Steps Assessed & $\begin{array}{l}\text { How } \\
\text { Feedback } \\
\text { Displayed }\end{array}$ & $\begin{array}{l}\text { Target of } \\
\text { Feedback }\end{array}$ & $\begin{array}{l}\text { Device } \\
\text { Compatibility }\end{array}$ & Cost & $\begin{array}{l}\text { FDA } \\
\text { Approval }\end{array}$ \\
\hline & $\begin{array}{l}\text { of inhalation to } \\
\text { actuation) }\end{array}$ & $\begin{array}{l}\text { as list of } \\
\text { events or } \\
\text { series of } \\
\text { graphs }\end{array}$ & & & & \\
\hline $\begin{array}{l}\text { An Inhaler } \\
\text { spacer } \\
\text { devices } \\
\text { comprised of } \\
\text { a microphone } \\
\text { to detect to } \\
\text { detect } \\
\text { inhalation } \\
\text { pressure } \\
\text { (Patent } \\
\text { Application: } \\
\text { US20150059 } \\
\text { 739A1) }\end{array}$ & $\begin{array}{l}\text { 4) breath in slowly } \\
\text { and deeply }\end{array}$ & $\begin{array}{l}\text { Incentive } \\
\text { graphic to } \\
\text { indicate } \\
\text { successful } \\
\text { inhalation }\end{array}$ & Patient & $\begin{array}{l}\text { MDI (with or } \\
\text { without } \\
\text { spacer) }\end{array}$ & Unknown & Unknown \\
\hline Mag-Flo & $\begin{array}{l}\text { Inhalation flow rate- } \\
\text { Courtney- can you } \\
\text { map onto ADMIT } \\
\text { steps? }\end{array}$ & $\begin{array}{l}\text { Green lights } \\
\text { turn on when } \\
\text { patient } \\
\text { reaches } \\
\text { minimum } \\
\text { inspiratory } \\
\text { flow and stay } \\
\text { on during } \\
\text { inhalation as } \\
\text { long as } \\
\text { patient } \\
\text { doesn't } \\
\text { inhaler too } \\
\text { fast or too } \\
\text { slow }\end{array}$ & Patient & $\begin{array}{l}\text { Diskus } \\
\text { Other DPI }\end{array}$ & $\begin{array}{l}\text { Courtney } \\
\text { check }\end{array}$ & $\begin{array}{l}\text { Courtney } \\
\text { check }\end{array}$ \\
\hline
\end{tabular}




\section{FIGURES}

Figure 1: Overview of Literature and Patent Review Process

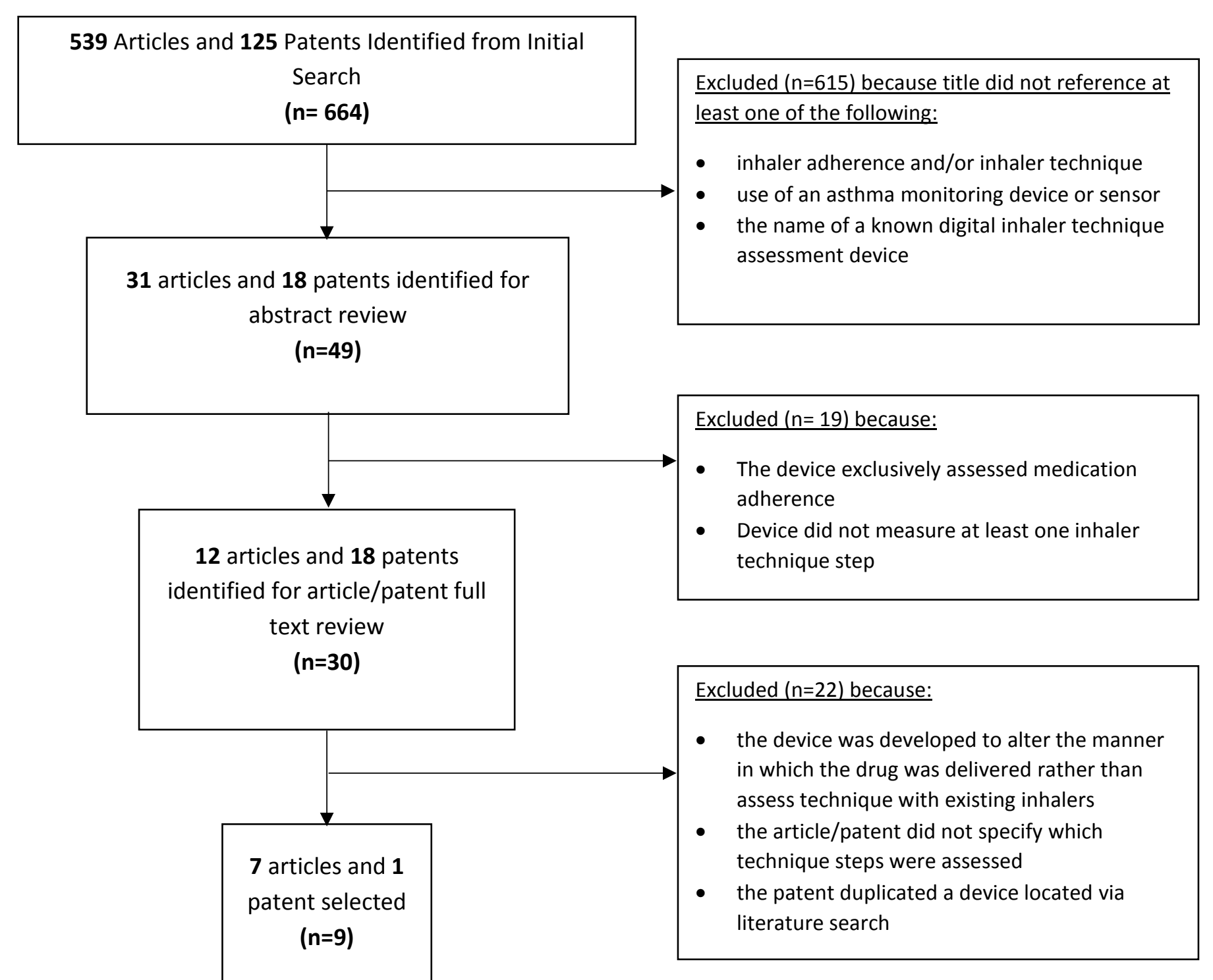

